\title{
Investigation of Effect of Abrasive Water Jet Machining (AWJM) Process Parameters on Performance Characteristics of High Carbon High Chromium Steel (AISI D3)
}

\author{
Sudhakar R. Lohar' ${ }^{1}$ Pravin R. Kubade ${ }^{2}$ \\ P. G. Scholar, Dept of Production Engg, K.I.T.'s College of Engineering, Kolhapur, Maharashtra, India ${ }^{1}$ \\ Asst. Professor, Dept of Production Engg, K.I.T.'s College of Engineering, Kolhapur, Maharashtra, India ${ }^{2}$
}

\begin{abstract}
This study investigates the influence of AWJM parameters on MRR and SR while machining of high carbon high chromium steel (AISI D3) material. The parameters considered are water pressure, feed rate, abrasive flow rate and stand-off distance. The experiments were performed on the abrasive water jet machine. The experiments planned, conducted and analysed using Taguchi method. It is found that the MRR is mainly influenced by feed rate; where as other factors have very less effect on material removal rate. Similarly SR at Top and Bottom are measured and analysed. Abrasive Water jet machining (AWJM) is a non-conventional manufacturing process, where material is removed from the work piece by impact erosion of pressurized high velocity water stream mixed with high velocity grit abrasives on a work piece. There are so many process parameters which affect the quality of machined surface cut by AWJM. But, the traverse speed, hydraulic pressure, stand-off distance, abrasive flow rate and type of abrasive are important. However, the important performance measures in AWJM are Material Removal Rate (MRR), Surface Roughness (SR). This work reports influence of process parameters of AWJM in machining AISI D3 material. It was confirmed that optimal combination of AWJM process parameters satisfy the real need for machining of AISI D3 in actual practice.
\end{abstract}

Keywords: AWJM, Process parameter, Process optimization, MRR, SR, ANOVA, L27 orthogonal array.

\section{INTRODUCTION}

Manufacturing industry is becoming more time conscious and residual stresses. AWJM has higher machining and quality oriented with the advancement in global versatility and better flexibility. The major drawback of economy. This becomes necessary to use non- this process is, it generate loud noise and a messy working conventional machining processes such as Chemical environment. AWJM have certain advantageous Machining, Laser Machining, Electric Discharge characteristics, which turns to achieve significant Machining, Abrasive Water Jet Machining, etc. Abrasive penetration into manufacturing industries [2].

water jet machining (AWJM) is a non-conventional machining process that employs high-pressure water for producing high velocity stream, entrained with abrasive particles for a wide variety of materials ranging from soft to hard. AWJM is a versatile machining process primarily used to machine materials ranging from soft to hard like titanium, inconel, etc. hard and difficult to machine materials [1].

Abrasive water jet machining makes use of the principles of both abrasive jet machining and water jet machining. The first industrial application manufactured by McCartney Manufacturing Company and installed in Alto Boxboard in year 1972. The invention of the abrasive water jet in 1980 and in 1983 the first commercial system with abrasive entrainment in the jet became available. This technique is mainly suitable for softer, brittle and fibrous materials. This process operates without heat generation so machined surface is free from heat affected zone (HAZ)

- Faster set-up and programming

- Less sensitive to material properties as it does not cause chatter

- Very little fixturing for most parts

- Machine virtually any two dimensional shape on any material

- No heat affected zone (HAZ) on part

- Machining thick plates

AWJM is normally used for applications like Paint removal, Cutting frozen meat, Surgery, Cutting, Pocket Milling, Turning, Drilling, Textile, Leather industry. Materials which are cut by AWJM are Steels, Non-ferrous alloys, Super alloys, Exotic materials, Ti alloys, Ni- alloys, Polymers, Metal Matrix Composite, Ceramic Matrix Composite ,high tech ceramics, Concrete, Wood, Plastics, Metal Polymer Laminates, etc.[3] 
IAR JSET

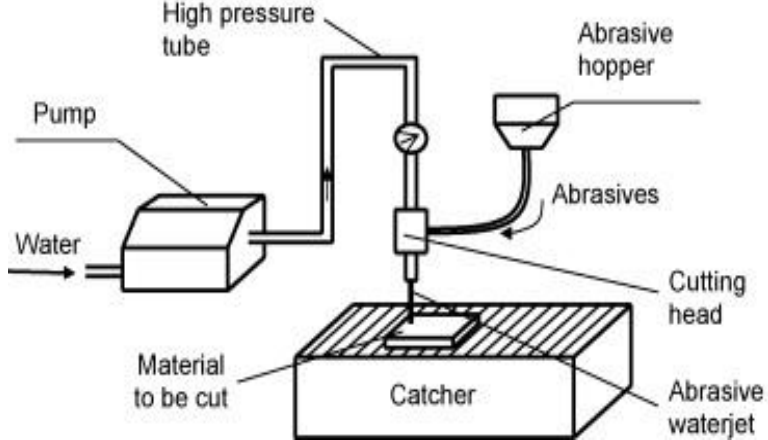

Fig.1. Abrasive Water Jet Machine Schematic Diagram

Non-traditional machining like AWJM has grown out of the need to machine these exotic materials. The problems of high complexity in shape, size and demand for product accuracy and surface finish can be solved through AWJM [4]. Abrasive Water jet Machining (AWJM) has also made its presence felt in the new fields such as sports, medical and surgical, instruments, optical, including automotive $\mathrm{R} \& \mathrm{D}$ areas and machining geometrically complex or hard material components, that are precise and difficult-to machine such as heat treated tool steels, titanium, composites, super alloys, ceramics, carbides, heat resistant steels etc. being widely used in die and mold making industries, aerospace, aeronautics and nuclear industries[5]. This work mainly focuses on optimization of process parameters in AWJM of AISI D3 material.

\section{EXPERIMENTATION}

\section{A. Materials}

AWJM is capable of machining geometrically complex and/or hard material components that are precise and difficult to machine such as heat treated tool steels, composites, super alloys, ceramics, carbides, heat resistant steels etc.[6]. We have selected the AISI D3 (High Carbon High Chromium Steel) material because it is widely used for industrial application in Pressure die casting dies, blanking and forming dies, cold trimmer dies or rolls, bending, forming and seaming rolls, plug gauges, drawing dies for bars or wires, slitting cutters, press tools, punches, forming rolls [7]. In this research work AISI D3 (density $7.7 \times 100 \mathrm{~kg} / \mathrm{m} 3$ ) selected as a specimen material. The size of rectangular specimen is $30 \mathrm{~mm} \times 25 \mathrm{~mm} \times 10 \mathrm{~mm}$. The material is hardened to a hardness of 55 HRC.Selected material is tested before used for experiments in material testing laboratory.

Chemical composition obtained is as per Table 1.

Table 1-Chemical Composition of AISI D3

\begin{tabular}{|l|l|l|l|l|l|}
\hline Material & $\mathbf{C}$ & $\mathbf{M n}$ & $\mathbf{S i}$ & $\mathbf{C r}$ & $\mathbf{S}$ \\
\hline \% Value & $\begin{array}{l}1.92- \\
2.35\end{array}$ & $\begin{array}{l}0.15- \\
0.6\end{array}$ & $\begin{array}{l}0.1- \\
0.6\end{array}$ & $\begin{array}{l}11.00- \\
13.50\end{array}$ & $\begin{array}{l}0.03- \\
\text { Max }\end{array}$ \\
\hline $\begin{array}{l}\text { Obtained } \\
\text { \% Value }\end{array}$ & 2.32 & 0.490 & 0.210 & 11.28 & 0.0690 \\
\hline
\end{tabular}

B. Experimental set up:

AWJM (CNC) machine of make 'Ab Best Matic -Ingersoll Rand (KMT), is used for experimental work. The operating and controlling of AWJM process can do through the display screen and a keyboard. Experimental set-up of AWJM process is as shown in figure 2. AWJM of high carbon high chromium steel (AISI D3) material will be carried out on Abrasive water jet machine. Specifications of abrasive water jet machine:

- Machine Model: Ab Best Matic -Ingersoll Rand (KMT) make

- Voltage : $415 \mathrm{~V}$

- Table Size : $1250 \mathrm{~mm}$ x $2000 \mathrm{~mm}$

- Pump : 50 HP KMT Jetline J- I 50 pressure pump

- Abrasive :Garnet 80 mesh

- Travel : X Axis: $2000 \mathrm{~mm}, \mathrm{Y}$ Axis: $1000 \mathrm{~mm}, \mathrm{Z}$ Axis: $120 \mathrm{~mm}$
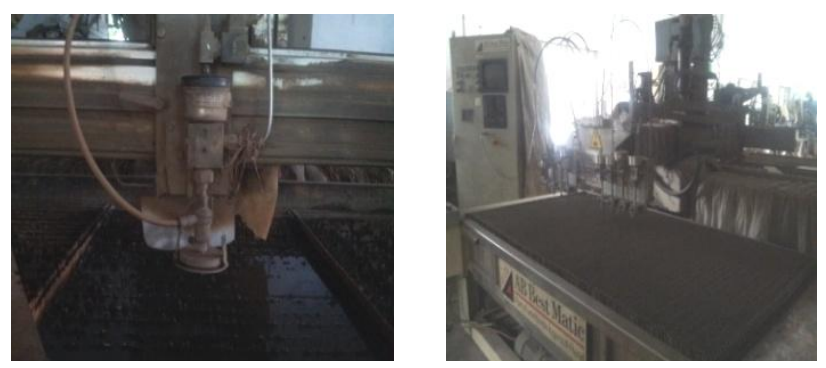

Fig.2. Experimental set up of Abrasive Water Jet Machine

C. Design of experiment based on Taguchi method: In this investigation carried out by varying four control factors water pressure, traverse feed rate, abrasive flow rate and SOD on AWJM .A Orifice diameter $0.25 \mathrm{~mm}$, Nozzle diameter $0.76 \mathrm{~mm}$, abrasive size garnet 80 mesh and Impact angle 900 were used as a constant for every experimental work. Control factors along with their levels are listed in Table 2. Hence Taguchi based design of experiment method was implemented. In Taguchi method L27 Orthogonal array provides a set of well-balanced experiments, and Taguchi's signal-to-noise. (S/N) ratios, which are logarithmic functions of the desired output, serve as objective functions for optimization.

This paper uses Taguchi method, which is very effective to deal with responses influenced by multi-variables. This method is a powerful Design of Experiments tool, which provides a simple, efficient and systematic approach to determine optimal machining parameters.

Compared to the conventional approach to experimentation, this method reduces drastically the number of experiments that are required to model the response functions. Traditional experimentation involves one-factor-at-a-time experiments, wherein one variable is changed while the rest are held constant. The major disadvantage of this strategy is that it fails to consider any possible interactions between the parameters. An 
IARJSET

International Advanced Research Journal in Science, Engineering and Technology

National Conference on Design, Manufacturing, Energy \& Thermal Engineering (NCDMETE-2017)

AGTI's Dr. Daulatrao Aher College Engineering, Vidyanagar Extension, Karad

Vol. 4, Special Issue 1, January 2017

interaction is the failure of one factor to produce the same effect on the response at different levels of another factor. It is also impossible to study all the factors and determine their main effects (i.e., the individual effects) in a single experiment. Taguchi technique overcomes all these drawbacks.

The main effect is the average value of the response function at a particular level of a parameter. The effect of a factor level is the deviation it causes from the overall mean response. The Taguchi method is devised for process optimization and identification of optimal combinations of factors for given responses.

The steps involved are:

1. Identify the response functions and the process parameters to be evaluated.

2. Determine the number of levels for the process parameters and possible interaction between them.

3. Select the appropriate orthogonal array and assign the process parameters to the orthogonal array and conduct the experiments accordingly.

4. Analyze the experimental results and select the optimum level of process parameters.

5. Verify the optimal process parameters through a confirmation experiment.

The process parameters chosen for the experiments are: (a) water pressure, (b) Traverse feed rate, (c) Abrasive flow rate and (d) stand-off distance while the response functions are: (a) Material Removal rate (MRR) and (b) Surface Roughness (SR).

According to the capability of the commercial AWJM machine available and general recommendations of machining conditions for AISI D3 the range and the number of levels of the parameters are selected as given in Table 2.

Table 2- Level values of input Factors

\begin{tabular}{|l|l|l|l|l|l|}
\hline $\begin{array}{l}\text { Sr. } \\
\text { No. }\end{array}$ & Parameters & Units & $\begin{array}{l}\text { Level } \\
\mathbf{1}\end{array}$ & $\begin{array}{l}\text { Level } \\
\mathbf{2}\end{array}$ & $\begin{array}{l}\text { Level } \\
\mathbf{3}\end{array}$ \\
\hline A & $\begin{array}{l}\text { Water } \\
\text { pressure }\end{array}$ & $(\mathrm{Psi})$ & 2500 & 3000 & 3500 \\
\hline B & Feed Rate & $\begin{array}{l}(\mathrm{mm} / \\
\mathrm{min})\end{array}$ & 54 & 75 & 120 \\
\hline C & $\begin{array}{l}\text { Abrasive } \\
\text { flow rate }\end{array}$ & $\begin{array}{l}(\mathrm{gm} / \\
\mathrm{min})\end{array}$ & 250 & 320 & 400 \\
\hline D & $\begin{array}{l}\text { Stand-off } \\
\text { distance }\end{array}$ & $(\mathrm{mm})$ & 2 & 3 & 4 \\
\hline
\end{tabular}

The experimental layout for the machining parameters using the L27 orthogonal array is shown in Table 3. A statistical analysis of variance (ANOVA) is performed to identify the process parameters that are statistically significant. Based on ANOVA the optimal combinations of the process parameters are predicted.
Table 3. Taguchi L27 Orthogonal Array Parametric Combinations:

\begin{tabular}{|c|c|c|c|c|}
\hline $\begin{array}{l}\text { Ex. } \\
\text { no. }\end{array}$ & $\begin{array}{l}\text { Water } \\
\text { Pressure } \\
\text { (psi) }\end{array}$ & $\begin{array}{l}\text { Feed } \\
\text { Rate } \\
(\mathrm{mm} / \mathrm{min})\end{array}$ & $\begin{array}{l}\text { Abrasive } \\
\text { flow rate } \\
(\mathrm{gm} / \mathrm{min})\end{array}$ & $\begin{array}{l}\text { Stand- } \\
\text { off dista } \\
\text { nce (mm) }\end{array}$ \\
\hline 1. & 2500 & 54 & 250 & 2 \\
\hline 2. & 2500 & 54 & 320 & 3 \\
\hline 3. & 2500 & 54 & 400 & 4 \\
\hline 4. & 2500 & 75 & 250 & 3 \\
\hline 5. & 2500 & 75 & 320 & 4 \\
\hline 6. & 2500 & 75 & 400 & 2 \\
\hline 7. & 2500 & 120 & 250 & 4 \\
\hline 8. & 2500 & 120 & 320 & 2 \\
\hline 9. & 2500 & 120 & 400 & 3 \\
\hline 10. & 3000 & 54 & 250 & 3 \\
\hline 11. & 3000 & 54 & 320 & 4 \\
\hline 12. & 3000 & 54 & 400 & 2 \\
\hline 13. & 3000 & 75 & 250 & 4 \\
\hline 14. & 3000 & 75 & 320 & 2 \\
\hline 15. & 3000 & 75 & 400 & 3 \\
\hline 16. & 3000 & 120 & 250 & 2 \\
\hline 17. & 3000 & 120 & 320 & 3 \\
\hline 18. & 3000 & 120 & 400 & 4 \\
\hline 19. & 3500 & 54 & 250 & 4 \\
\hline 20. & 3500 & 54 & 320 & 2 \\
\hline 21. & 3500 & 54 & 400 & 3 \\
\hline 22. & 3500 & 75 & 250 & 2 \\
\hline 23. & 3500 & 75 & 320 & 3 \\
\hline 24. & 3500 & 75 & 400 & 4 \\
\hline 25. & 3500 & 120 & 250 & 3 \\
\hline 26. & 3500 & 120 & 320 & 4 \\
\hline 27. & 3500 & 120 & 400 & 2 \\
\hline
\end{tabular}

D. Experimental procedure:

Experiments are performed, randomly, according to the L27 orthogonal array, on AISI D3 plate of size $30 \mathrm{~mm} \times 25 \mathrm{~mm} \times 10 \mathrm{~mm}$. The cutting tool path is set at fixed for all experiments. The machining time is noted from the timer of the machine. The readings, at different parametric combinations, are taken. The surface roughness is measured at top and bottom section (at distance $2.5 \mathrm{~mm}$ from top and bottom surface) of each specimen.
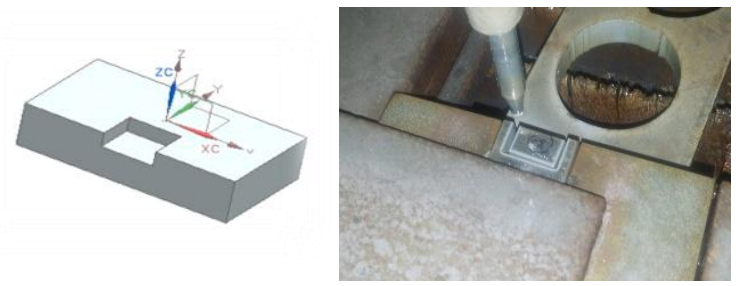

Fig. 3 Fixture for Specimen

The geometry of the specimen is drawn on UNIGRAPHICS NX 9 software. Geometry is defined in forms of different definitions of points, lines. Tool path or cutting path is given by programmer by using Heidenhain 
IARJSET

International Advanced Research Journal in Science, Engineering and Technology

National Conference on Design, Manufacturing, Energy \& Thermal Engineering (NCDMETE-2017) AGTI's Dr. Daulatrao Aher College Engineering, Vidyanagar Extension, Karad

Vol. 4, Special Issue 1, January 2017

controller. Geometry of specimen used in current experimentation is as shown in figure 4 as below.

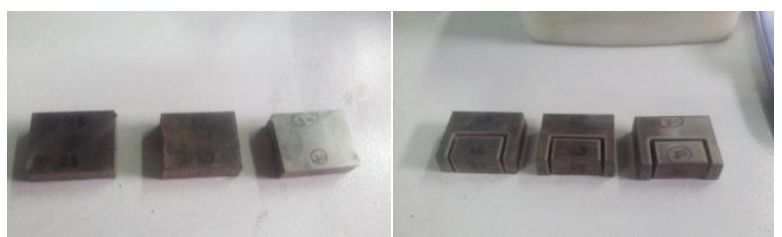

Fig.4. Specimen before Cut and After Cut for illustration

The work pieces are cleaned properly before and after each machining run and the respective weights are taken by an electronic weighing machine (make: Shinko Denshi; Model no-AJ-620E) of accuracy $\pm 0.002 \mathrm{~g}$.During AWJM process, water jet cutting produces a crater on the specimen. Hence this surface roughness is measured by stylus on surface roughness tester. Stroke length selected for present experiment is $0.25 \times 5 \mu \mathrm{m}$. The surface roughness is measured using Surface Roughness tester (Mitutoyo-Japan make; Model-SJ201P). Surface roughness of machined face of specimen is measured as shown in figure 5.
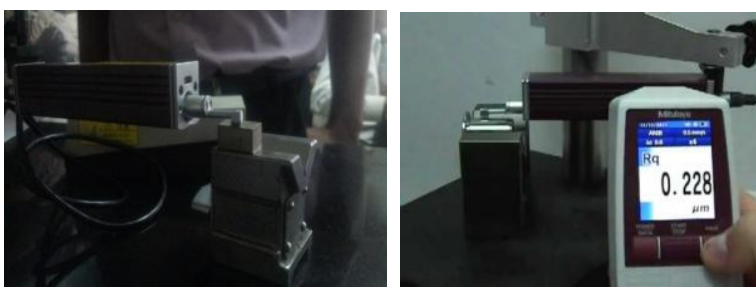

Fig. 5 Surface Roughness tester

The experimental results for MRR and SR based on L27 orthogonal array is shown in Table 4.

Table4: Experimental Results for MRR \& SR

\begin{tabular}{|c|c|c|c|}
\hline $\begin{array}{l}\text { Expt. } \\
\text { No. }\end{array}$ & $\begin{array}{l}\text { MRR } \\
(\mathbf{g m} / \mathbf{m i n})\end{array}$ & $\begin{array}{c}\text { SR TOP } \\
\text { (micron) }\end{array}$ & $\begin{array}{c}\text { SR BOTTOM } \\
\text { (micron) }\end{array}$ \\
\hline 1 & 0.05935 & 4.568 & 12.594 \\
\hline 2 & 0.06049 & 4.056 & 6.335 \\
\hline 3 & 0.06690 & 3.784 & 4.306 \\
\hline 4 & 0.07826 & 4.525 & 10.501 \\
\hline 5 & 0.08528 & 5.974 & 9.225 \\
\hline 6 & 0.09315 & 3.127 & 11.246 \\
\hline 7 & 0.11973 & 6.22 & 11.409 \\
\hline 8 & 0.11827 & 4.947 & 10.958 \\
\hline 9 & 0.12302 & 5.3 & 9.673 \\
\hline 10 & 0.06367 & 3.925 & 9.4 \\
\hline 11 & 0.06824 & 3.456 & 4.444 \\
\hline 12 & 0.06640 & 4.192 & 5.574 \\
\hline 13 & 0.08534 & 4.523 & 12.701 \\
\hline 14 & 0.08472 & 4.656 & 8.126 \\
\hline 15 & 0.09542 & 3.637 & 6.819 \\
\hline 16 & 0.11041 & 6.11 & 8.002 \\
\hline 17 & 0.12412 & 4.082 & 9.639 \\
\hline 18 & 0.12671 & 4.089 & 7.863 \\
\hline 19 & 0.06792 & 3.59 & 7.036 \\
\hline
\end{tabular}

\begin{tabular}{|c|c|c|c|}
\hline 20 & 0.06798 & 4.042 & 4.338 \\
\hline 21 & 0.06985 & 3.4 & 4.715 \\
\hline 22 & 0.09179 & 4.234 & 7.665 \\
\hline 23 & 0.08963 & 3.34 & 10.939 \\
\hline 24 & 0.09884 & 4.717 & 4.107 \\
\hline 25 & 0.13214 & 4.395 & 11.909 \\
\hline 26 & 0.12657 & 6.28 & 18.712 \\
\hline 27 & 0.12588 & 4.632 & 12.241 \\
\hline
\end{tabular}

\section{RESULTS AND DISCUSSION}

After the experimental procedure, different response factors like MRR, SR TOP and SR BOTTOM of the material were calculated from the observed data. Then a statistical analysis were performed on the calculated values and the signal to noise ratio values of three response factors are tabulated in table 5 .

Table5: Signal to noise ratio for various response factors.

\begin{tabular}{|c|c|c|c|}
\hline $\begin{array}{l}\text { Expt. } \\
\text { No. }\end{array}$ & $\begin{array}{l}\text { S/N Ratio } \\
\text { for MRR }\end{array}$ & $\begin{array}{c}\text { S/N Ratio } \\
\text { for SR TOP }\end{array}$ & $\begin{array}{l}\text { S/N Ratio for } \\
\text { SR BOTTOM }\end{array}$ \\
\hline 1 & -24.56 & -13.19 & -22 \\
\hline 2 & -24.36 & -12.16 & -16.03 \\
\hline 3 & -23.49 & -11.56 & -12.68 \\
\hline 4 & -22.13 & -13.11 & -20.42 \\
\hline 5 & -21.38 & -15.52 & -19.3 \\
\hline 6 & -20.61 & -9.9 & -21.02 \\
\hline 7 & -18.43 & -15.87 & -21.14 \\
\hline 8 & -18.54 & -13.88 & -20.79 \\
\hline 9 & -18.2 & -14.48 & -19.71 \\
\hline 10 & -23.92 & -11.87 & -19.46 \\
\hline 11 & -23.32 & -10.77 & -12.95 \\
\hline 12 & -23.87 & -12.45 & -14.92 \\
\hline 13 & -21.37 & -13.1 & -22.07 \\
\hline 14 & -21.44 & -13.36 & -18.19 \\
\hline 15 & -20.4 & -11.21 & -16.67 \\
\hline 16 & -19.65 & -15.72 & -18.06 \\
\hline 17 & -18.12 & -12.21 & -19.68 \\
\hline 18 & -17.94 & -12.23 & -17.91 \\
\hline 19 & -23.36 & -11.1 & -16.94 \\
\hline 20 & -23.35 & -12.13 & -12.74 \\
\hline 21 & -23.11 & -10.63 & -13.47 \\
\hline 22 & -20.74 & -12.53 & -17.69 \\
\hline 23 & -20.95 & -10.47 & -20.78 \\
\hline 24 & -20.1 & -13.47 & -12.27 \\
\hline 25 & -17.58 & -12.86 & -21.51 \\
\hline 26 & -17.95 & -15.96 & -25.44 \\
\hline 27 & -18 & -13.31 & -21.75 \\
\hline
\end{tabular}

The experimental results are analyzed, to see the main effects and the difference between the main effect of level 1, 2 and 3 of the variables on the MRR, SR TOP and SR BOTTOM using the MINITAB 17.

A. Effect of input factors on MRR

The response table for signal to noise ratio for MRR is shown in table 6 and corresponding analysis variances 
IARJSET

International Advanced Research Journal in Science, Engineering and Technology

National Conference on Design, Manufacturing, Energy \& Thermal Engineering (NCDMETE-2017)

AGTI's Dr. Daulatrao Aher College Engineering, Vidyanagar Extension, Karad

Vol. 4, Special Issue 1, January 2017

(ANOVA) table is shown in table 7 for MRR, the calculation of S/N ratio follows "Larger the better model".

Table 6. Response table for signal-to- noise ratio for MRR.

\begin{tabular}{|l|l|l|l|l|}
\hline Level & WP & FR & AFR & SoD \\
\hline 1 & -21.29 & -21.70 & -21.30 & -21.19 \\
\hline 2 & -21.11 & -21.01 & -21.04 & -20.97 \\
\hline 3 & -20.57 & -18.26 & -20.63 & -20.81 \\
\hline Delta & 0.72 & 3.44 & 0.67 & 0.38 \\
\hline Rank & 2 & 1 & 3 & 4 \\
\hline
\end{tabular}

Table 7. Analysis of Variance (ANOVA) for MRR

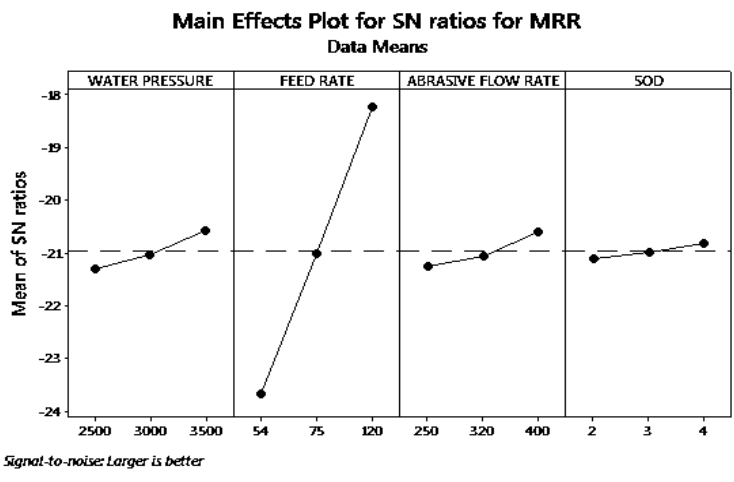

Fig. 6 Graph showing S/N ratio for MRR

\begin{tabular}{|l|l|l|l|l|l|l|}
\hline Source & DF & Seq SS & Adj SS & Adj MS & F & P \\
\hline WATER PRESS-URE & 2 & 0.0002546 & 0.0002546 & 0.0001273 & 9.20 & 0.002 \\
\hline FEED RATE & 2 & 0.0149539 & 0.0149539 & 0.0074769 & 540.25 & 0.000 \\
\hline ABRASIVE FLOW RATE & 2 & 0.0001950 & 0.0001950 & 0.0000975 & 7.04 & 0.005 \\
\hline SOD & 2 & 0.0000440 & 0.0000440 & 0.0000220 & 1.59 & 0.232 \\
\hline Error & 18 & 0.0002491 & 0.0002491 & 0.0000138 & & \\
\hline Total & 26 & 0.0156966 & & & & \\
\hline
\end{tabular}

Statistical Values for regression Analysis for MRR:

$\mathrm{S}=0.00372020 \quad \mathrm{R}-\mathrm{Sq}=98.41 \% \quad \mathrm{R}-\mathrm{Sq}(\operatorname{adj})=97.71 \%$

The regression equation is

MRR $=-0.0185+0.000007$ WATER PRESSURE + 0.000850 FEED RATE+ 0.000043 ABRASIVE FLOW RATE + 0.00153 SOD

The graph (Fig. 6) shows that MRR is maximum in the case of Water Pressure at level 3 (3500), in case of Feed Rate at level 3 (120), in case of Abrasive flow rate MRR will be maximum at level3 (400) and in case of Stand-off distance at the level 3 (4).As the feed rate increases the MRR increases and decreases as fees rate decreases.

Analysis of variance is performed to find out the significant parameter which affects the material removal rate. With help ANOVA table 7, significant process parameters for particular response are identified.

B. Effect of input factors on SR TOP

The response table for signal to noise ratio for SR TOP is shown in table 8 and corresponding analysis variances (ANOVA) table is shown in table 9 for SR TOP, the calculation of $\mathrm{S} / \mathrm{N}$ ratio follows "Smaller the better model".
Table 8: Response table for S/N Ratio for SR TOP, smaller the better

\begin{tabular}{|c|c|c|c|c|}
\hline Level & WP & FR & AFR & SoD \\
\hline 1 & -13.29 & -11.76 & -13.26 & -12.94 \\
\hline 2 & -12.54 & -12.52 & -12.94 & -12.11 \\
\hline 3 & -12.49 & -14.05 & -12.13 & -13.28 \\
\hline Delta & 0.8 & 2.29 & 1.13 & 1.17 \\
\hline Rank & 4 & 1 & 3 & 2 \\
\hline
\end{tabular}

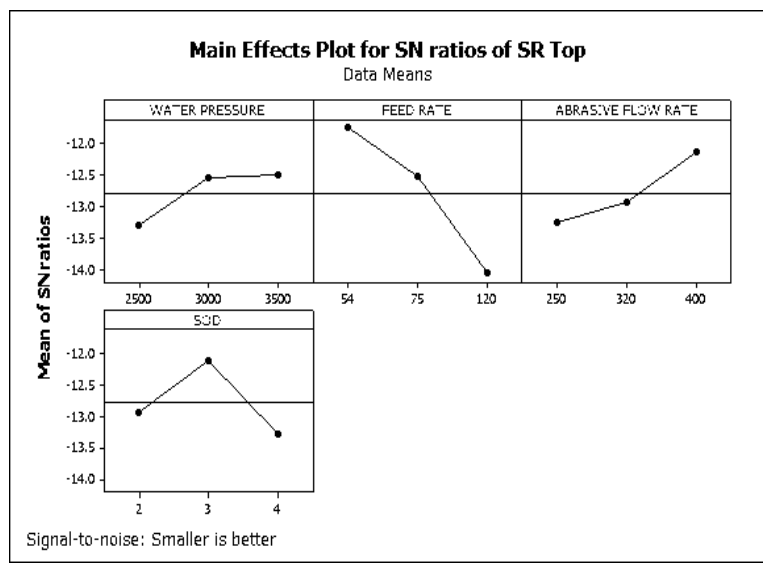

Fig. 7 Graph showing S/N ratio for SR TOP

Table 9. Analysis Of Variance (ANOVA) for SR TOP

\begin{tabular}{|l|l|l|l|l|l|l|}
\hline Source & DF & Seq SS & Adj SS & Adj MS & F & P \\
\hline WATER PRESSURE & 2 & 1.0986 & 1.0986 & 0.5493 & 1.12 & 0.347 \\
\hline FEED RATE & 2 & 7.0139 & 7.0139 & 3.5070 & 7.17 & 0.005 \\
\hline ABRASIVE FLOW RATE & 2 & 1.6440 & 1.6440 & 0.8220 & 1.68 & 0.214 \\
\hline SOD & 2 & 2.0370 & 2.0370 & 1.0185 & 2.08 & 0.154 \\
\hline
\end{tabular}


IARJSET

International Advanced Research Journal in Science, Engineering and Technology

National Conference on Design, Manufacturing, Energy \& Thermal Engineering (NCDMETE-2017)

AGTI's Dr. Daulatrao Aher College Engineering, Vidyanagar Extension, Karad

Vol. 4, Special Issue 1, January 2017

\begin{tabular}{|l|l|l|l|l|l|l|}
\hline Error & 18 & 8.7996 & 8.7996 & 0.4889 & & \\
\hline Total & 26 & 20.5931 & & & & \\
\hline
\end{tabular}

Statistical Values for regression Analysis for SR TOP are$\mathrm{S}=0.699189 \mathrm{R}-\mathrm{Sq}=57.27 \% \quad \mathrm{R}-\mathrm{Sq}(\operatorname{adj})=38.28 \%$

The regression equation is SR TOP $=5.10-0.000430$ WATER PRESSURE +0.0185 FEED RATE- 0.00390 ABRASIVE FLOW RATE + 0.118 SOD

The graph (Fig. 7) shows that SR TOP will be minimum in the case of Water Pressure at level 3 (3500), in case of Feed Rate at level 1(54), in case of Abrasive flow rate SR TOP will be maximum at level3 (400) and in case of Stand-off distance at the level 2 (3).

Analysis of variance is performed to find out the significant parameter which affects the surface roughness at top. With help of ANOVA Table 9, significant process parameters for particular response are identified.

Traverse Feed Rate has maximum effect on SR. Water pressure and abrasive flow rate have negligible effect on material removal rate whereas stand-off distance has moderate effect on SR TOP.

\section{Effect of input factors on SR BOTTOM}

The response table for signal to noise ratio for SR BOTTOM is shown in table 10 and corresponding analysis variances (ANOVA) table is shown in table 11 for SR BOTTOM, the calculation of $\mathrm{S} / \mathrm{N}$ ratio follows "Smaller the better model".
Table 10: Response table for S/N Ratio for SR BOTTOM, smaller the better.

\begin{tabular}{|l|l|l|l|l|}
\hline Level & WP & FR & AFR & SoD \\
\hline 1 & -19.23 & -15.68 & -19.92 & -18.57 \\
\hline 2 & -17.76 & -18.71 & -18.43 & -18.63 \\
\hline 3 & -18.06 & -20.66 & -16.71 & -17.85 \\
\hline Delta & 1.47 & 4.98 & 3.21 & 0.78 \\
\hline Rank & 3 & 1 & 2 & 4 \\
\hline
\end{tabular}

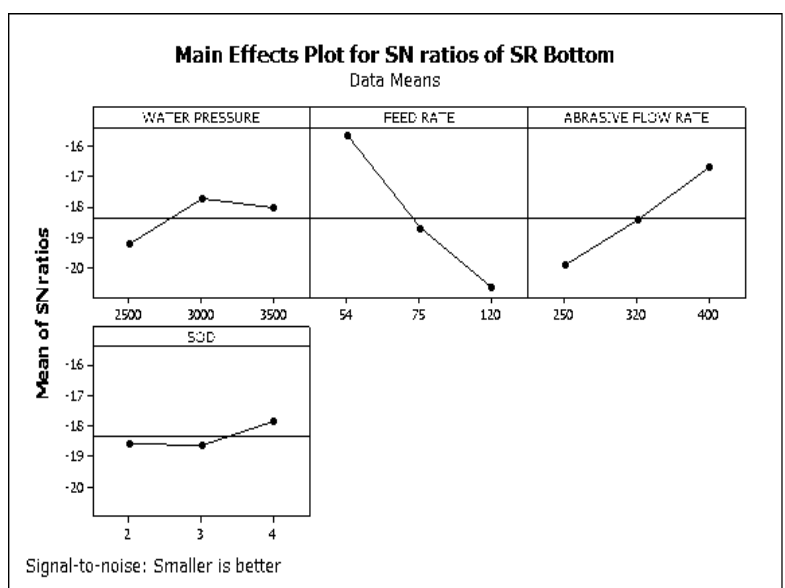

Fig. 8 Graph showing S/N ratio for SR BOTTOM

Table 11. Analysis Of Variance (ANOVA) for SR BOTTOM

\begin{tabular}{|l|l|l|l|l|l|l|}
\hline Source & DF & Seq SS & Adj SS & $\begin{array}{l}\text { Adj } \\
\text { MS }\end{array}$ & F & P \\
\hline WATER PRESSURE & 2 & 10.772 & 10.772 & 5.386 & 0.61 & 0.553 \\
\hline FEED RATE & 2 & 96.666 & 96.666 & 48.333 & 5.50 & 0.014 \\
\hline ABRASIVE FLOW RATE & 2 & 34.910 & 34.910 & 17.455 & 1.99 & 0.166 \\
\hline SOD & 2 & 0.058 & 0.058 & 0.029 & 0.00 & 0.997 \\
\hline Error & 18 & 158.145 & 158.145 & 8.786 & & \\
\hline Total & 26 & 300.550 & & & & \\
\hline
\end{tabular}

Statistical Values for regression Analysis for SR at bottom. With help of ANOVA table 11, significant BOTTOM are -

$\mathrm{S}=2.96409 \mathrm{R}-\mathrm{Sq}=47.38 \% \quad \mathrm{R}-\mathrm{Sq}(\mathrm{adj})=24.00 \%$

The regression equation is

process parameters for particular response are identified.

Traverse Feed Rate has maximum effect on SR. Abrasive flow rate also have moderate influence on SR at bottom SR BOTTOM = $11.0-0.00051$ WATER PRESSURE + whereas water pressure and stand-off distance has 0.0665 FEED RATE- 0.0184 ABRASIVE FLOW RATE - negligible effect on SR BOTTOM.

0.052 SOD

The graph (Fig. 8) shows that SR BOTTOM will be minimum in the case of Water Pressure at level 2 (3000), in case of Feed Rate at level 1 (54), in case of Abrasive flow rate SR BOTTOM will be maximum at level 3 (400) and in case of Stand-off distance at the level 3 (4).

Analysis of variance is performed to find out the significant parameter which affects the surface roughness

\section{CONCLUSION}

This paper presents analysis of various process parameters and on the basis of experimental results, analysis of variance (ANOVA), F-test and SN Ratio.

The following conclusions can be drawn for effective machining of High Carbon High Chromium Steel (AISI D3) by AWJM process as follows: 


\section{IAR JSET}

- Traverse Feed Rate is the most significant factor for MRR during AWJM. Meanwhile Water pressure, Abrasive Flow Rate and Stand-off distance are sub significant in influencing. The parametric combination for optimum material removal rate is WP3-FR3-AFR3SOD3.The optimal parameter setting for the MRR found (3500-120-400-4).

- In case of Surface Roughness at top Feed Rate is most significant control factor and hence the optimum recommended parametric combination for optimum surface Roughness isWP3-FR1-AFR3-SOD2.The optimal parameter setting for the SR TOP found (3500-54-400-3).

- In case of Surface Roughness at bottom Feed Rate is most significant control factor and hence the optimum recommended parametric combination for optimum surface Roughness isWP2-FR1-AFR3-SOD3.The optimal parameter setting for the SR BOTTOM found(3000-54400-4)

It is concluded that the feed rate plays a significant role in governing high MRR and low SR. The confirmation experiment performed with the above combinations results in MRR as $0.149 \mathrm{~mm} 3 / \mathrm{min}$ and SR at Top and Bottom as $3.534 \mu \mathrm{m}$ and $5.544 \mu \mathrm{mrespectively} \mathrm{showing} \mathrm{improvement.}$ As a result, optimization of the performance characteristics of the AWJM such as MRR and SR are improved together by using the method proposed by this study.

\section{REFERENCES}

[1] Er. Guru SewakKesharwani, "Controlled Depth Milling of Ti-6Al4V Alloy using Non-spherical (Triangular \& Trapezoidal) Sharp edge shape ceramics abrasive particle in Abrasive Water Jet Machining",International Journal of Scientific \& Engineering Research, Volume 6, Issue 5,pp. 183-188, 2015.

2] ChithiraiPonSelvan M, Sampath S S, Sawan Shetty, Shivamurthy B, "Investigation of Abrasive Water jet Cutting Surfaces of Alumina Ceramics", International Journal of Emerging Technology and Advanced Engineering, Volume 5, Issue 1, pp.402-407, 2015.

[3] Ramprasad, Gaurav Upadhyay, Kamal Hassan, "Optimization MRR Of Stainless Steel 403 In Abrasive Water Jet Machining Using Anova And Taguchi Method", International Journal of Engineering Research and Applications, Volume 5, Issue 5, pp. 86-91, 2015.

[4] Vishal Gupta, P.M. Pandey, Mohinder Pal Garg, Rajesh Khanna,N.K.Batra, "Minimization of kerf taper angle and kerf width using Taguchi's method in abrasive water jet machining of marble", In Proceedings of the Third International Conference on Materials Processing and Characterization (ICMPC 2014),Procedia Materials Science 6, pp. 140 - 149, 2014.

[5] P. Shanmughasundaram, "Influence of Abrasive Water jet machining parameters on surface roughness of Eutectic $\mathrm{Al}-\mathrm{Si}$ Alloy-Graphite Composites", Journal of Materials Physics and Mechanics 19, pp. 1-8, 2014.

[6] D. Sidda Reddy, A. Seshu Kumar, M.Sreenivasa Rao, "Parametric Optimization of Abrasive Water Jet Machining of Inconel $800 \mathrm{H}$ Using Taguchi Methodology" , Universal Journal of Mechanical Engineering 2(5), pp. 158-162, 2014.

[7] M.Sreenivasa Rao, S.Ravinder and A. Seshu Kumar, "Parametric Optimization of Abrasive Water jet Machining for Mild Steel: Taguchi Approach", International Journal of Current Engineering and Technology, Special Issue-2, pp. 28-30, 2014.
] UshastaAicha, Simul Banerjee, AsishBandyopadhyay, Probal Kumar Das, "Abrasive Water Jet Cutting of Borosilicate Glass”, In Proceedings of the Third International Conference on Materials Processing and Characterisation (ICMPC 2014),Procedia Materials Science 6, pp. $775-785,2014$

[9] K.S. Jai Aultrin, M. DevAnand, "Optimization of Machining Parameters in AWJM Process for an Copper Iron Alloy Using RSM and Regression Analysis", International Journal of Emerging Engineering Research and Technology, Volume 2, Issue 5, pp. 1934, 2014.

[10] DerzijaBegic-Hajdarevic , AhmetCekic, MuhamedMehmedovic, AlminaDjelmic, "Experimental Study on Surface Roughness in Abrasive Water Jet Cutting", In Proceedings of the Twenty Fifth International Symposium on Intelligent Manufacturing and Automation, DAAAM 2014, pp. 394 - 399, 2015.

[11] B.Satyanarayana,G. Srikar, "Optimization of Abrasive water jet machining using TGRA", In Proceedings of the Thirteenth IRF International Conference, ISBN: 978-93-84209-37-7, pp. 135-140, 2014

[12] Deepak Doreswamy, AkashValavala, NattWinitthumkul, AnjaiahDevineni, "Machining of D2 Heat treated steel using AWJ: Effect of Standoff distance and feed rate on kerf width and surface roughness", International Journal of Research in Engineering and Technology, Volume: 03, Issue: 08, pp.417-421, 2014

[13] T. V. K. Gupta, J. Ramkumar, "Role of Process Parameters on Pocket Milling with Abrasive Water Jet Machining Technique", International Journal of Mechanical, Aerospace, Industrial, Mechatronic and Manufacturing Engineering Vol:7, No:10, pp. 946-951, 2013

[14] G.A Escobar-Palafox, R.S Gault, K Ridgway, "Characterization of abrasive water-jet process for pocket milling in Inconel 718 ", 5th CIRP Conference on High Performance Cutting 2012, Procedia CIRP 1, pp. 404 - 408, 2012.

[15] Pravin R.Kubade,V.S.Jadhav, "An Experimental Investigation of Electrode Wear Rate (EWR),MaterialRemoval Rate (MRR) andRadial Overcut (ROC) in EDM of High Carbon-High Chromium Steel (AISI D3)", International Journal of Engineering and Advanced Technology (IJEAT),Volume 1,Issue 5, pp. 135-140, 2012

[16] Pravin R. Kubade, Sunil S. Jamadade, Ravindranath G. Kshirsagar, Rahul C. Bhedasgaonkar, "Parametric Study and Optimization of WEDM Parameters for Titanium diboride TiB2",Volume 2,Issue 4, pp. $1-5,2015$

[17] Sudhakar R. Lohar and Pravin R. Kubade "Current Research and Development in Abrasive Water Jet Machining (AWJM): A Review” IJSR-Volume 5 Issue 1, pp. 996-999, 2016.

\section{BIOGRAPHIES}

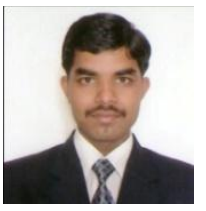

Sudhakar R. Lohar, Scholar of M.E. Mechanical-Production Engineering, K.I.T.'s College of Engineering, Kolhapur-416234, Maharashtra, India.

Pravin R. Kubade, Asst. Prof., Department of Mechanical and Production Engineering, K.I.T.'s College of Engineering, Kolhapur-416234, Maharashtra, India. 